\title{
Evaluation of flood hazard maps in print and web mapping services as information tools in flood risk communication
}

\author{
M. Hagemeier-Klose and K. Wagner \\ Chair of Forest and Environmental Policy, Technische Universität München, Freising, Germany \\ Received: 20 October 2008 - Revised: 18 March 2009 - Accepted: 25 March 2009 - Published: 9 April 2009
}

\begin{abstract}
Flood risk communication with the general public and the population at risk is getting increasingly important for flood risk management, especially as a precautionary measure. This is also underlined by the EU Flood Directive. The flood related authorities therefore have to develop adjusted information tools which meet the demands of different user groups. This article presents the formative evaluation of flood hazard maps and web mapping services according to the specific requirements and needs of the general public using the dynamic-transactional approach as a theoretical framework. The evaluation was done by a mixture of different methods; an analysis of existing tools, a creative workshop with experts and laymen and an online survey.

The currently existing flood hazard maps or web mapping services or web GIS still lack a good balance between simplicity and complexity with adequate readability and usability for the public. Well designed and associative maps (e.g. using blue colours for water depths) which can be compared with past local flood events and which can create empathy in viewers, can help to raise awareness, to heighten the activity and knowledge level or can lead to further information seeking. Concerning web mapping services, a linkage between general flood information like flood extents of different scenarios and corresponding water depths and real time information like gauge levels is an important demand by users. Gauge levels of these scenarios are easier to understand than the scientifically correct return periods or annualities. The recently developed Bavarian web mapping service tries to integrate these requirements.
\end{abstract}

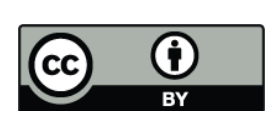

Correspondence to:

M. Hagemeier-Klose

(hagemeier@forst.wzw.tum.de)

\section{Introduction}

Flood risk management and flood risk communication are key words in dealing with floods in our century as we have been facing major flood events with massive damage during the last decades. In Germany, extreme flood events in 1997 on the Oder, in 2002 on the Danube and on the Elbe, and in 1999 and 2005 in Southern Bavaria, have shown that we need to rethink our strategies in terms of coping with major floods. In addition, frequency and intensity of flood events in Europe may increase in future as a result of climate change and therefore create new challenges for science on the one hand and authorities and the public on the other hand (EU, 2007).

Flood risk management includes three main aspects; precaution, coping, and recovering (Kienholz and Krummenacher, 1995). In this context, precaution is the most effective protection against flood damages. As a precautionary measure, the new German water legislation and the European Directive on the Assessment and Management of Flood Risks (EU Flood Directive) demand more detailed and extensive preparation of flood hazard or flood risk maps. Furthermore, the high frequency of flood events in Europe and globally over the last years shows an increasing need to provide precise and extensive information to the general public and especially to people at risk so as to prevent future damages. Therefore, risk communication is an important element of the newly implemented EU Flood Directive.

The EU Flood Directive requires that the member states develop three different kinds of products. The first step includes a preliminary flood risk assessment to judge the risk level of all regions and to define those regions in which flood maps and flood risk management plans have to be established. This step shall be completed by 2011 . The second step, which is to be realised by 2013 , is the preparation of flood hazard and flood risk maps. The flood hazard maps should show different flood scenarios; a flood event with

Published by Copernicus Publications on behalf of the European Geosciences Union. 
high probability, a flood event with medium probability, and a rare (or extreme) flood event with low probability. The flood risk maps are designed to describe potential adverse consequences of specific flood scenarios. These maps form a prerequisite for the flood risk management plans. This is the final implementation step requested by the directive. The plan should indicate the management objectives and the corresponding measures. The directive requires that these information tools have to be available to the general public. Moreover, an active involvement of all interested parties in the production, review, and updating of the flood risk management plans is desired.

Flood hazard or risk maps serve as a basis for spatial planning, for local hazard assessment, for emergency planning, and for planning technical protection measures (Excimap, 2007). Of course, these maps are essential for awareness building and for communication about the local hazard situation, the extension of the legally designated flood plain, and the use of restrictions. Taking this into account, we can state that flood maps serve a variety of purposes and have to fulfil the various demands of the different user groups. Therefore, user group involvement is essential for acceptance and usability of the map products. For this paper, the user group "general public" is our main interest group.

The flood related authorities in Europe increasingly use the Internet as a platform for risk communication with the public. The advantages of the Internet are independency of time and location, up-to-dateness, participation and interaction possibilities, as well as diverse visualisation options (Barth, 2004). Moreover, an increasing part of the population is connected to the Internet. But still this media is mainly used by highly educated and younger people (ARD/ZDF, 2003).

In Germany, first efforts are being made to implement the EU Flood Directive. The federal states have all started to set up different types of flood maps as a basis for the flood management plans. In Bavaria the project FloodScan, supported by the EU-Life-Programme, is facilitating this process. Within this project, data processing and software development for 2d-modelling of flood plains and flood hazard maps will be optimized and adjusted for large scale application. Furthermore, best practice flood hazard maps will be developed based on national and international concepts (e.g. provided by the German federal working group on water (LAWA, 2007) or the European Exchange Circle on Flood Mapping (Excimap, 2007)) and in co-ordination with (inter)national experts. To guarantee a comprehensive extensive, easily understandable and target-group specific provision of information on flood plains and flood hazard areas, the results are visualized in a web mapping service. In 2004, the Bavarian environment agency (LfU) launched a public web mapping service showing detailed information on flood plains (www.iug.bayern.de). Improvements will be carried out based on the formative evaluation. Because of this project framework, Bavaria is the focus area of our study.
The paper shows evaluation results of flood hazard maps in print and web mapping services used for informing the general public about flood risks. The evaluation is aimed at contributing to improved flood risk communication by improving map products for the general public while taking into account the special needs and requirements of this user group according to content, readability and usability.

The next chapter will describe our theoretical framework and how it is connected to risk communication. In the following part we present the results of the formative evaluation of the information tools flood hazard maps and web mapping services. These form the basis for the relaunch of the Bavarian web mapping service. Concluding remarks on risk communication with the help of flood maps complete the paper.

\section{Flood risk communication and the dynamic- transactional approach}

Flood risk communication is used to inform the population about flood risks, flood protection, and personal safety measures. Risk communication is defined as an interactive information exchange between individuals, groups or institutions, about the nature of risks, risk related opinions, anxieties and coping strategies (Wiedemann and Schütz, 2000; Wiedemann and Mertens, 2005). Risk communication is closely linked to risk perception, as only perceived risks are communicated and communication also influences the perception of risks. Moreover, risk communication plays a significant role within risk management.

The aim of risk communication is to strengthen people's risk awareness and to motivate the population at risk to take preventive actions and to be prepared for an emergency case. The current flood risk management in Germany and other European countries aims at more self-responsibility of the population at risk for their own safety. As current surveys show, the minority of the people living in flood risk areas feel or are actually prepared for future flood events. Selfresponsibility of the population at risk for own safety measures is an upcoming target of flood risk management. But only a part of the population at risk is aware that they should make their own preparations for a flood event, and only a few of them are actually doing anything. Usually, the people think and prefer to see flood protection as the responsibility of the authorities (Steinführer et al., 2008). However, knowledge about flood risks is a necessary basis and a pre-condition for preliminary actions such as precautionary measures, insurance, or active search for further information sources. With risk communication, the knowledge level about risks, for example, about the local hazard situation should be improved. Surveys on risk perception in Germany, Austria and Switzerland have shown that people's risk assessment with regards to their own residential area differs greatly to the risk assessment of the responsible authorities. The personal living place is usually perceived to 
be relatively safe from natural hazards although people live in high risk areas (Schrems, 1998; Siegrist and Gutscher, 2006; PLANAT, 2004; Hagemeier-Klose, 2007). Information tools in flood risk communication aim to reduce these different assessments and to inform the people about risks in their residential zone. Another aim of risk communication is to minimize upcoming conflicts, e.g. when dealing with the regulation of flood plains which have legal and financial consequences for inhabitants and land owners (Wiedemann and Schütz, 2000; Ruhrmann, 2003; Hertel and Henseler, 2005). Additionally, risk communication is used for trust building to increase the confidence of the general public in the responsible authorities. The more the acceptance of risks and of corresponding protection measures increases, the more people trust the relevant institutions (Zwick and Renn, 2008).

People are not only passive, they are also active recipients of risk information that is individually processed and assessed. Risk communication has to be adjusted to the specific needs of the people at risk to give them the possibility of judging their own risk situation in an objective way and of making informed decisions according to preparedness and personal safety measures. Therefore, this evaluation takes into account the requirements and the needs of the user group of the general public according to the dynamic-transactional approach (Früh and Schönbach, 1982, 1991, 2005). In this approach the users (in our case the general public) and the communicators (in our case the flood related authorities) are both passive and active. The communicator actively selects and provides information but is passive in having to cope with the conditions set by the media platform (e.g. the Internet) and the users. The flood related authorities select the information, assess the importance and then communicate the information to the public via different types of media. The user is active in the selection and in the elaboration processes, but he is passive in the sense that he is almost totally unable to choose what information is provided. The approach assumes that initial contact with information is stimulated by the message. This causes the user to react in a physiological reflex and to pay attention. Subsequently, the user ascribes subjective meaning to the message. Again, this process has an interacting component; receiving information may lead to a simultaneous increase of the activation level, i.e. an increased interest in a certain topic, for example, floods. The general public can usually evaluate which flood information is relevant and decide which additional information is sought. The combination of increased information and interest then leads to more favourable conditions for taking up other information in this area (Früh and Schönbach, 1982, 1991, 2005). Therefore, the initial message in flood risk communication is very important to gain the interest and attention of the people at risk. A good initial message could be a well designed flood map which can lead to a high attention level and to further information seeking by the users. Because of these facts, the design and usability of flood maps to suit the users' needs is essential for effective risk communication.

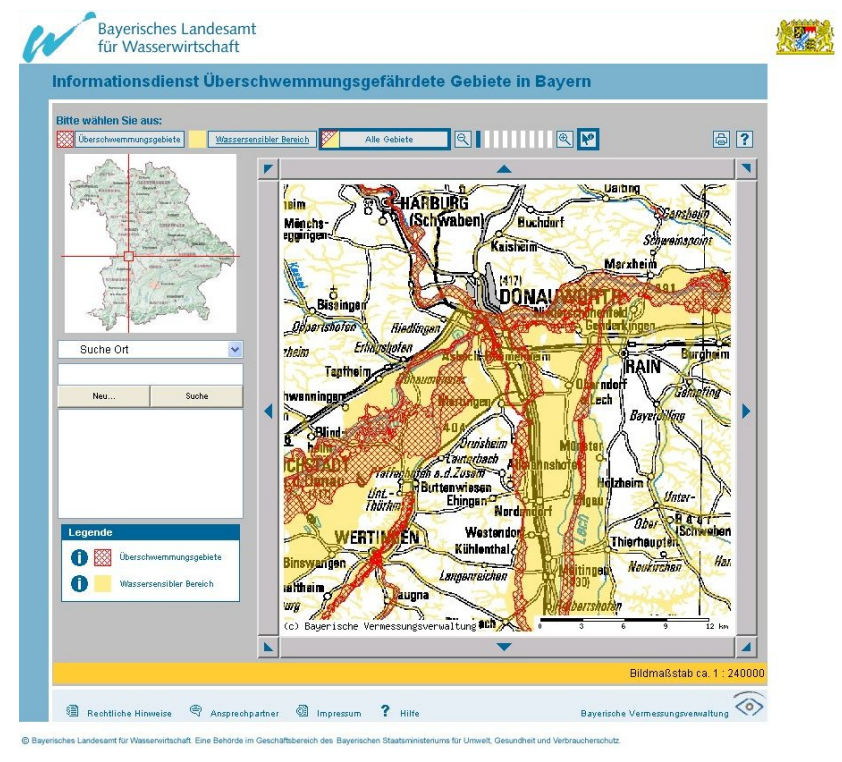

Fig. 1. Information service flood plains in Bavaria (Informationsdienst Überschwemmungsgefährdete Gebiete in Bayern) (www. bayern.de/LFW/iug/).

\section{Methods of evaluation}

Evaluation research can be subdivided into formative and summative evaluation. While the summative evaluation tries to find out if the goals of, for example, an information tool are achieved, the formative evaluation helps to optimize the development process to meet the requirements of the user groups. In a formative evaluation qualitative as well as quantitative empirical methods are used with laymen and experts as evaluators (Wottawa and Thierau, 2003). Our first evaluation step was to analyse summatively the state of the art. The workshop, our second step, follows a formative evaluation approach and should bring together laymen from the general public and experts to discuss and evaluate examples of the already analysed existing tools and newly developed flood maps and web mapping services in order to gain insight into their requirements. The third step of our evaluation, also formative, deals with a concrete example of a web mapping service, which will be further developed in our research project. This web mapping service is analysed in all three evaluation steps.

\subsection{Analysis of existing flood maps and web-mapping services}

As a first research step, an analysis of existing information tools was carried out between December 2006 and April 2007 to gain an overview of present public relations work of the authorities responsible for flood management. The countries analysed - Germany, Austria, Switzerland, the Netherlands and Great Britain - have all started to implement flood 
Table 1. Typology of examples of current web mapping services and web GIS.

\begin{tabular}{|c|c|c|c|c|}
\hline & national level & State, canton, province level & catchment/regional level & local level, communities \\
\hline information system & & Salzburg GIS & & \\
\hline $\begin{array}{l}\text { GIS-functionality illustration of } \\
\text { one or multiple natural hazards }\end{array}$ & & GIS Zürich & & \\
\hline complex information-system & & & IAN information & \\
\hline $\begin{array}{l}\text { complex information-system } \\
\text { illustration of one natural } \\
\text { hazard }\end{array}$ & $\begin{array}{l}\text { eHORA - Flood } \\
\text { risks in Austria }\end{array}$ & $\begin{array}{l}\text { Saarland GIS } \\
\text { designated flood } \\
\text { plains }\end{array}$ & & \\
\hline \multirow{2}{*}{$\begin{array}{l}\text { web mapping service } \\
\text { illustration of multiple } \\
\text { natural hazards }\end{array}$} & Risk map & hazard indication & & \\
\hline & Netherlands & map Luzern & & \\
\hline \multirow{2}{*}{$\begin{array}{l}\text { web mapping service } \\
\text { illustration of one } \\
\text { natural hazard }\end{array}$} & & in Bavaria & Mosel Hazard Atlas & administrative district \\
\hline & & $\begin{array}{l}\text { flood hazard } \\
\text { maps Sachsen }\end{array}$ & & of Schwäbisch-Hall \\
\hline
\end{tabular}

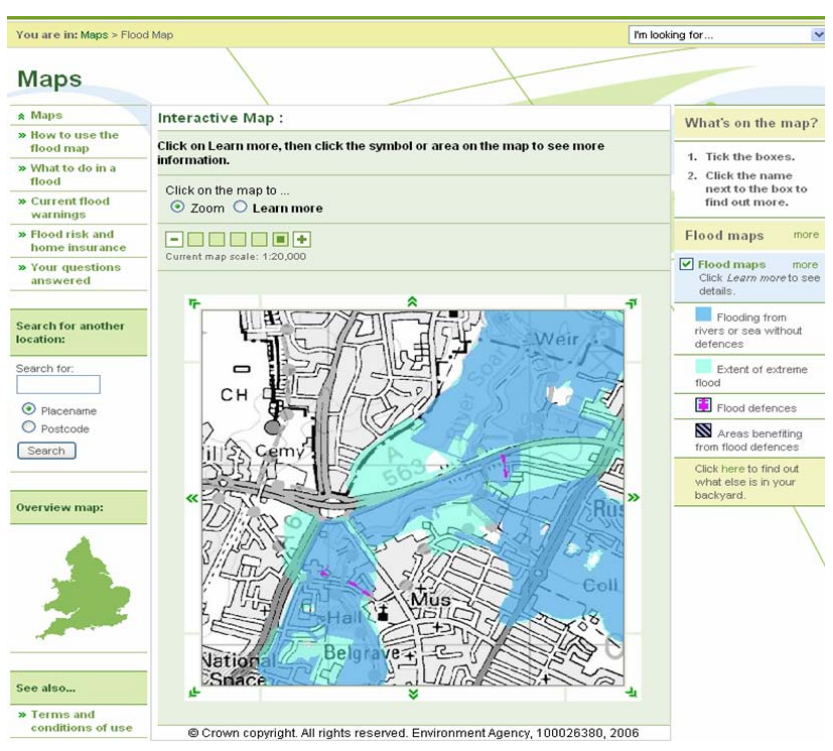

Fig. 2. Web-mapping-service of the Environment Agency (UK) (http://maps.environment-agency.gov.uk/wiyby/mapController).

hazard or flood risk maps according to the EU Flood Directive. Moreover, different Web-GIS or web mapping services dealing with flood topics can be found in these countries. The Internet information services were already analysed with an expert evaluation (Hagemeier-Klose and Wagner, 2008).

\subsection{Creative workshop}

As a second step, we realised an interdisciplinary creative workshop in July 2007 with the aim of getting experts and laymen to discuss and to evaluate different information tools in flood risk communication together. We chose 24 participants according to their professional background or interest in flood topics, for example, laymen living in flood risk areas, to get a mixed group with a great diversity of experiences, opinions and perceptions. The participants can be subdivided into experts from different disciplines and laymen (Table 1). Within the workshop, 50 different examples of imaginary and existing flood hazard maps and three examples of web applications were discussed and evaluated to further develop these instruments and to formulate requirements on such information tools. The flood hazard maps were elaborated for the German community Rieden which is located on the river Vils in the FloodScan research area. The virtual maps were developed according to the different existing map products described above, using different map backgrounds, different colours or signatures and different contents. The guidelines of the LAWA (2007) and EXCIMAP (2007) were also included. Each participant was asked to evaluate the maps according to three different criteria: readability; design and visualisation; content. Later on the best evaluated maps were discussed in the whole workshop group. In addition, three different existing web mapping services were presented and evaluated by the experts and laymen using a moderated discussion. 


\subsection{Online survey}

The existing web mapping service of Bavaria, the so called "information service about flood plains and flood prone areas in Bavaria (Informationsdienst Überschwemmungsgefährdete Gebiete in Bayern, IÜG)", was already evaluated within the first two evaluation steps. For a concluding evaluation of this service, we implemented an online survey among the users between 13 June and 14 August 2007. All visitors to the welcome page of the service, were asked to take part in the survey. The problem of online surveys is that we cannot be sure if the respondents meet our real survey population. We have to be aware of the fact that mainly intensive users and users highly interested in the flood topic answered our questionnaire. Our survey returned 175 analysable questionnaires with at least one third of the questions answered. The survey included questions about the assessment of the actual performance of the web mapping service, about useful extensions and improvement possibilities. The results were analysed user group specifically.

The findings of these three steps serve as a basis for the further development of this Internet information tool, in which the service is adapted to the users' requirements.

\section{Results of formative evaluation of flood maps and web mapping services as information tools in flood risk communication}

This chapter presents the evaluation results of flood maps used for informing the general public about flood risks. We carried out the evaluation according to the dynamictransactional approach. By this we mean that we investigated the needs and requirements of the user group of the general public and developed ways to improve map products which lead to increased awareness and a heightening of knowledge about flood topics. As the users actively decide whether to $\mathrm{read} /$ look at flood maps or not and actively decide whether to seek further flood information or not, our target is to make the maps as good and as interesting as possible. Essential aspects are especially the visual component, easily understandable content, and the offer of further information. Because of the aspects mentioned, the results should help to improve flood risk communication by optimizing map products. These take into account the special needs and requirements of the user group of the general public as far as content, readability and usability are concerned.

We are aware that there is no general public and that the public consists of different social groups, but we are convinced that there are some overall needs and requirements on flood maps that should be fulfilled when improving risk communication for the public. Many studies use the term laymen to distinguish between expert and laymen characteristics (Slovic, 1987; Jungermann and Slovic, 1193; Siegrist

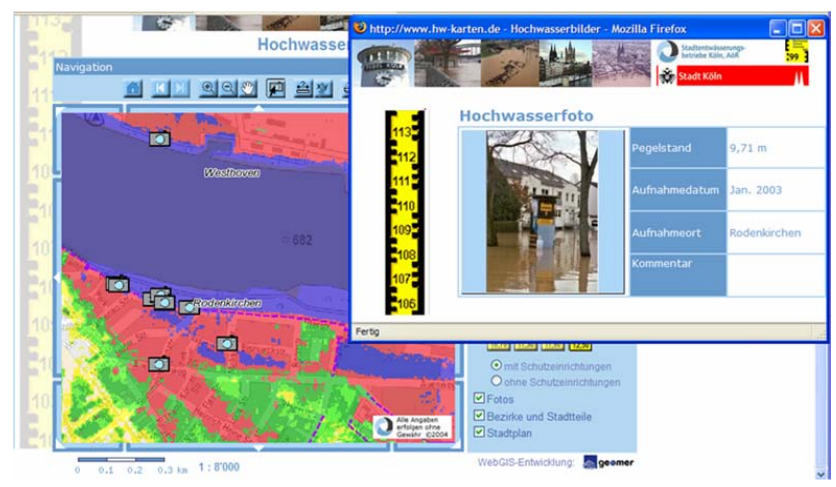

Fig. 3. Flood hazard map Cologne (http://www.hw-karten.de/ koeln/).

and Gutscher, 2006). To simplify, we assume that the general public usually has laymen characteristics when dealing with flood topics. So if we talk, for example, about usability for laymen, we assume that these results can be adopted for the general public as well.

\subsection{Evaluation of existing flood maps and web mapping services}

In this chapter, existing types of flood maps and Internet services are evaluated according to their advantages and disadvantages for risk communication with the general public. Moreover, some examples are given to further illustrate the outcomes.

As mentioned above, the EU Flood Directive demands the development of flood hazard maps and flood risk maps by all member states. The countries analysed in this paper have already started to create flood hazard maps or hazard zone maps but the implementation level still is very different. The fact that many different approaches and implementations exist, constitutes a major problem for the water authorities. Three main approaches to flood hazard maps exist in the analysed countries. In Germany for instance, there are maps showing the legally designated flood plains. These maps are usually based on the 100-year flood and have direct legal consequences such as a construction ban and restrictions on use (WHG 31b). In Great Britain the flood map, showing the extent of the one hundred year flood in combination with the extent of an extreme flood event (1000-year flood), serves as a tool for risk communication in terms of awareness raising. However, it only aims at informing the communities, other planning authorities and the public about flood risks, but does not include any legal consequences (Environment Agency 2008, see Fig. 2). In Switzerland, the flood hazard maps show two different hazard zones derived from a combination of intensity and probability of exceedence of an event. This combination makes them one of the most advanced hazard maps in Europe. The different zones are connected to corresponding legal consequences. In the red hazard zone, there 


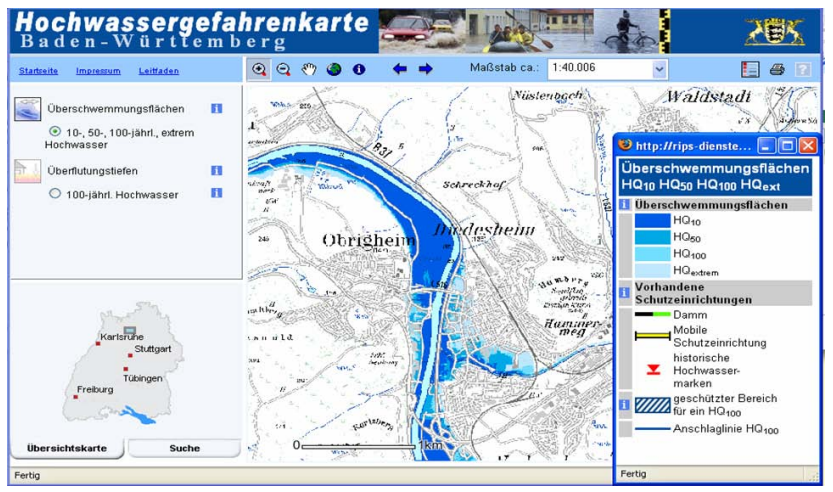

Fig. 4. Flood hazard map Baden-Württemberg (http://www. hochwasser.baden-wuerttemberg.de/servlet/is/15783).

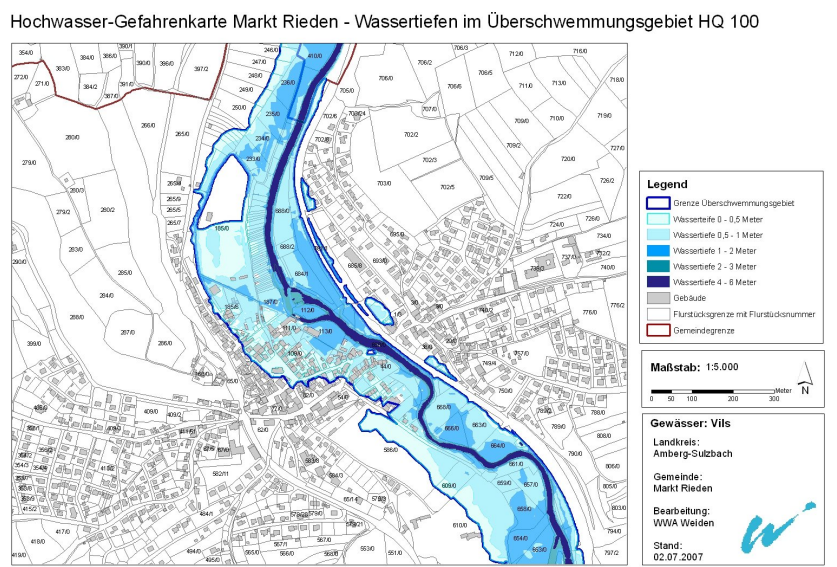

Fig. 5. Imaginary flood hazard map with blue colours for water levels.

is a stringent construction ban. The blue zone restricts the construction of new buildings and requires appropriate protection measures (Swiss Law for Spatial Planning - RPG). Similar approaches can be found in other countries as well, for example in Austria or South Tyrol.

The information communicated via these maps includes extensions of floods with different probabilities, water depths or flow velocities. In the majority of cases, the 100-year flood is used as the basis and is designated as a medium flood event by the EU Flood Directive. The water depths are already implemented in some actual flood hazard maps. But still, the flood extension map or flood plain map is the most widely distributed information tool in Europe (Excimap, 2007). Some existing examples available via the Internet are shown in Figs. 1-4.

Table 1 gives an overview of existing GIS and web mapping services and subdivides them into different spatial levels and into different complexity categories. On the national level, there are Internet information tools reaching from a complex flood information system in Austria, to simple web mapping services showing different natural risks (the Nether-

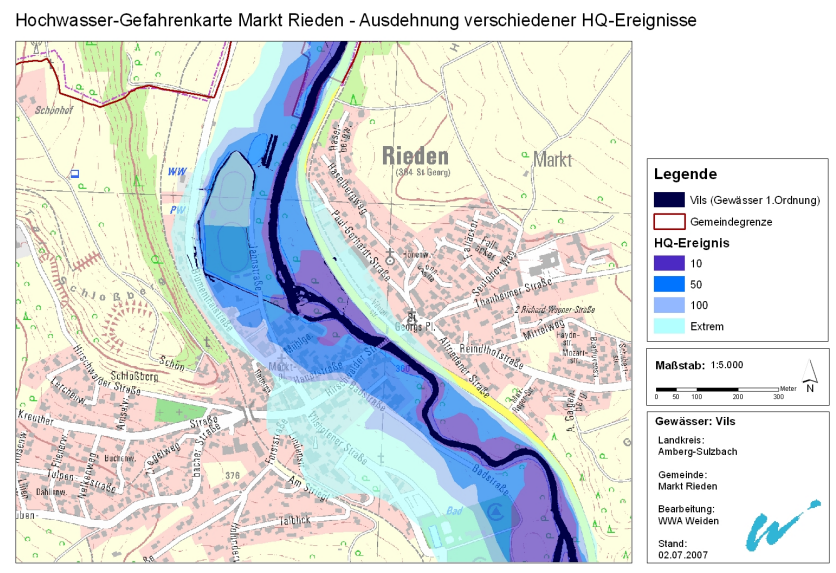

Fig. 6. Imaginary flood hazard map with different flood events.

lands), or just flood plains (UK). Complex geographical information services dealing also with natural hazards can only be found on provincial or state level in Austria, Germany and Switzerland. On the regional or local level there are usually only simple web mapping services (despite the Bavarian IAN). Regarding usability for experts and for the general public, we can state that all existing maps and services in the analysed countries are either too simple or too complex. Too much different information and too many functions reduce readability and usability, especially for the general public. A complex web GIS usually is too challenging for most laymen. Less information and reduced functionality, however, diminishes the usefulness for experts. A good balance between simplicity and complexity with adequate readability and usability is still missing. Different information tools, which meet either the specific needs of experts or of laymen, seem to be an adequate solution for this problem (HagemeierKlose and Wagner, 2008).

\subsection{Formative evaluation of flood hazard maps and web mapping services - results of a creative workshop}

The results of the creative workshop are influenced by the special legal situation in Germany. Legally designated flood zones in which a building ban exists as well as the flood hazard and risk maps according to the EU Flood Directive will be implemented (BMU, 2008). The participants of the creative workshop demanded that flood hazard maps, which aim to inform the public about floods, have to be easily understandable, clearly arranged, and accompanied with clear and simple explanations for laymen. Technical terminology should be avoided where possible. The legend and the category classes have to be comprehensible and readable at first sight. To create or strengthen local risk awareness, they should be combined and compared with past local flood events. Concerning visual aspects, flood hazard maps should meet the recipient's expectations and therefore be elaborated 


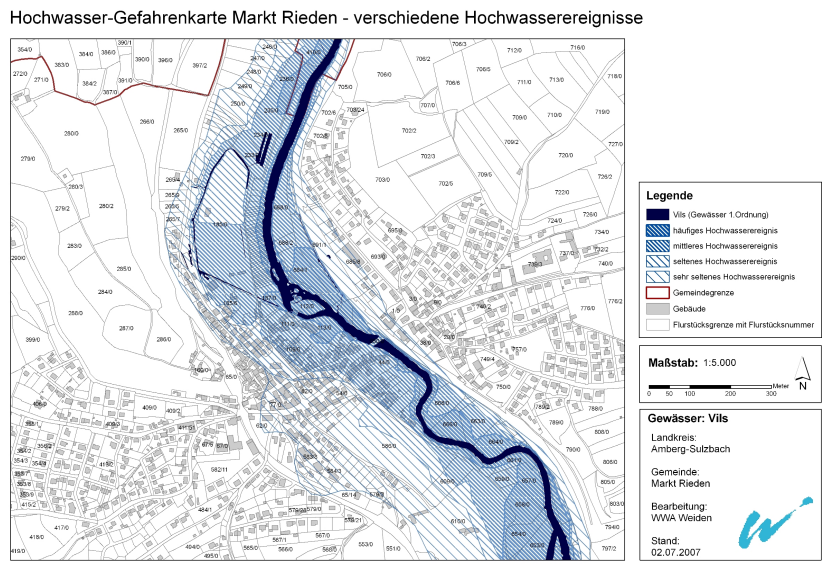

Fig. 7. Imaginary flood hazard map with LAWA terminology and blue hatching.

in blue colours which can be associated with water, e.g. water depths. The colours implemented in the Swiss hazard maps (red, blue, yellow for hazard zones) or the LAWA (purple for water depths in closed systems and red, blue, yellow for hazard zones) do not meet these expectations and are therefore inappropriate for risk communication with the public.

In our creative workshop, the preference of the evaluators with regards to the background of the maps differ in accordance with the contents shown on the flood maps. The legally protected flood plain or the water depths within the one hundred year flood should be presented on the digital land register map, because the land owner must be able to recognise his own parcel of land. Figure 5 shows an example of water levels within the one hundred year flood, which is in this case also the legally protected flood plain. When dealing with the extension of flood events with different return periods or with different hazard zones, a digital city plan or an orthophoto should be used as background because of the easier orientation possibilities for laymen. Figure 6 presents an imaginary map showing flood events with different return periods on the digital city plan.

Talking about map contents, we have to distinguish between maps showing one event, e.g. the one hundred year flood, and maps showing different events or different hazard or risk zones. For risk communication with the general public, the evaluating experts at the workshop recommend using a flood map which shows the legally protected flood plain, as well as a map dealing with flood events of different frequency and magnitude or different hazard zones. This combination of maps should help to raise awareness of flood risks outside the designated flood plain, for example, the risks of an extreme flood event.

To prevent technical terminology, the labels for flood events designed by the LAWA should be used for public risk communication. Here, the scale reaches from "very frequent flood events" to "very rare (or extreme) flood events"
Frequent flood (equivalent to ca. 2,50m at gauge station Amberg, 10-year flood)

Medium flood (equvalent to ca. $3,80 \mathrm{~m}$ at gauge station Amberg, 100-year flood)

Seldom/Extreme flood (equivalent to ca. $5,20 \mathrm{~m}$ at gauge station Amberg 1000-year flood/extreme flood)

\begin{abstract}
Definition:
A 100-year flood is a statistical term created by scientific models or by analysis of past flood events. A 100-year flood occurs on an average once in 100 years. Of course in extreme cases, there can also be multiple 100-year floods in 5 years.
\end{abstract}

Fig. 8. Possible legend for a flood hazard map.

(LAWA, 2007). According to the European Floods Directive, the one hundred year flood is a flood event with medium probability. Figure 7 shows one of the maps developed for the workshop using this terminology. Moreover, this figure uses blue hatchings to show the frequency of the flood event presented.

The best tool for risk communication with the public is the use of gauge levels to inform about flood risks as the population at risk can compare these water levels to flood situations in the past or to the actual water levels shown within the flood information services. A possible legend of a flood hazard map, combining different scenarios with gauge levels and an explanation, is illustrated in Fig. 8. According to layout design, base maps and colour design, the same findings can be adopted for web mapping services. During the creative workshop, the Bavarian service IÜG (Fig. 1), the Austrian geographic information system of Kärnten (Fig. 9), and the flood hazard maps of the city of Cologne (Fig. 3) were evaluated.

The Bavarian tool at present is a simple mapping service with reduced interactivity and little functionality but with good readability and adequate explanations for the general public. The Austrian Kärnten Atlas is a complex geographic information system with diverse functions for expert use. For laymen, the readability and usability of this tool is restricted because of its high complexity and the lack of background information about the hazards and possible precautionary actions. Moreover, here, floods are only one of many spatial topics and information. The flood hazard maps of Cologne perform well in usability and readability although the legend is hidden. A very positively assessed feature is the combination of water depth with real pictures of past flood events. Moreover, the extension and the water depths are associated with different water levels of the gauge in Cologne, which is easily comprehensible to the user.

From the recipient's point of view, there are different requirements for an optimal web mapping service. Summing 


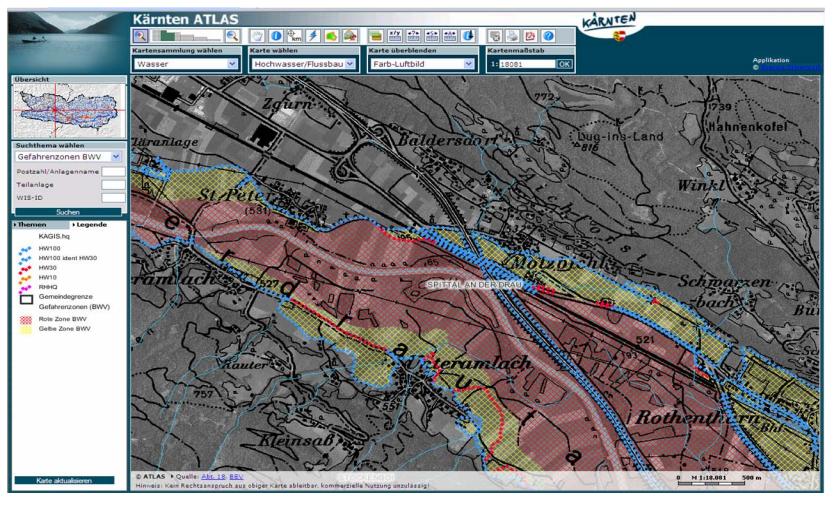

Fig. 9 Kärnten Atlas (http://gis.ktn.gv.at/atlas/(S(0vknwzeqrmwx1z552b2qxkvc))/init. aspx).

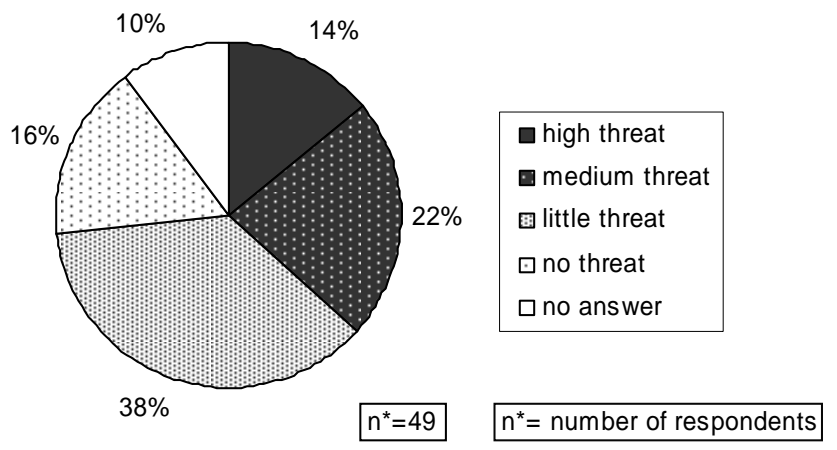

Fig. 10. Personal feeling of own flood threat.

up, there is a need for an integration of such a service into a broader Internet portal with different kinds of flood information. Moreover, it is important to provide target group specific information tools for both experts and laymen. For laymen, a simple web mapping service with real-time information and good usability and readability seems to be adequate. The demands of experts are better met by a complex web GIS with diverse download functions that allow further data processing. Regarding content, at least various layers indicating the extensions and water depths of flood events with different return periods should be realised. Additionally, an overview map and precise definitions and explanations have to be included. A combination with pictures of historical and recent floods is useful for effective risk communication as pictures can emotionally affect the viewers (Lopes, 1992). With regards to functionality, at least different layers, zoom or search options, and object selection for background information should be available.

Riskcatch, a project within the European Crue EraNet, achieved similar results (Crue Eranet, 2008). The project team worked on the optimum way of presenting hazard und risk maps to the public by analysing the eye movement and fixation times of test persons. Rather simple map products

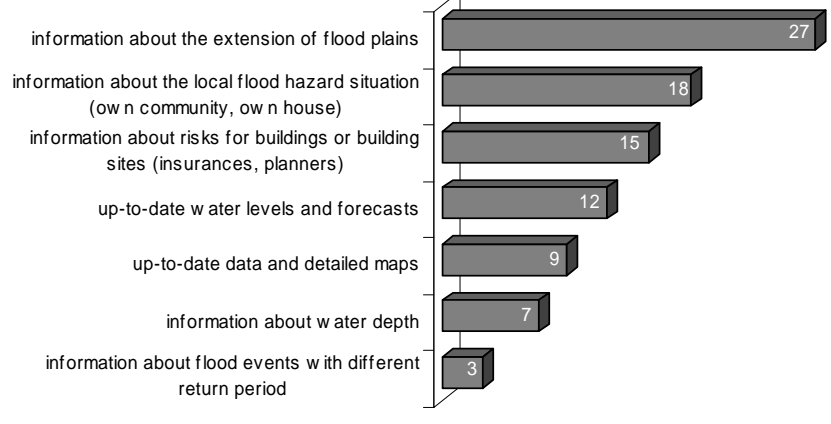

Fig. 11. Expectations of the users' relation of number of mentions.

with clear colours and clear contrast ratios can lead to a good understanding of the flood maps. Moreover, the results show that experts and laymen tend to look at flood maps in different ways. The legend, for example, is more important for expert users. Laymen keep their eyes on the middle of the map for longer with significantly less fixation on the legend or other explanations. Therefore, we can conclude that for the general public the map message has to be identified at first glance. The findings of this project strengthen our conclusions that different map products are needed for different user groups, and that the general public needs to be integrated into the development of flood hazard maps and web mapping services.

\subsection{Formative evaluation of the Bavarian web mapping service - results of the online survey}

In the following part, the results of the formative evaluation of the Bavarian web mapping service IÜG will be presented. The survey sample contains $48 \%$ professional (mainly working in authorities or private planning agencies) and $52 \%$ private users. $83 \%$ of the survey participants were male. Our sample consists mainly of participants with high education (46\% with university degrees) who classify themselves as belonging to the middle and upper classes of society $(73 \%$ middle and upper class). This finding is supported by the fact that $71 \%$ of the interviewees possess their own house or their own flat. A large number (84\%) had already experienced at least one flood event, but nevertheless they judged their own flood risk rather low (see Fig. 10). This corresponds with other survey results as mentioned in Sect. 2.

The IÜG is usually found through: targeted seeking of flood information, hints coming from the own authority/business company, or by following a link from the official authority web page. The survey participants had diverse expectations about what the IÜG should deliver. The most important expectations concerned information about hazard situations, up-to-date information or current water levels (Fig. 11).

With regard to the fulfilment of expectations, no significant differences was found between the two user groups, but 


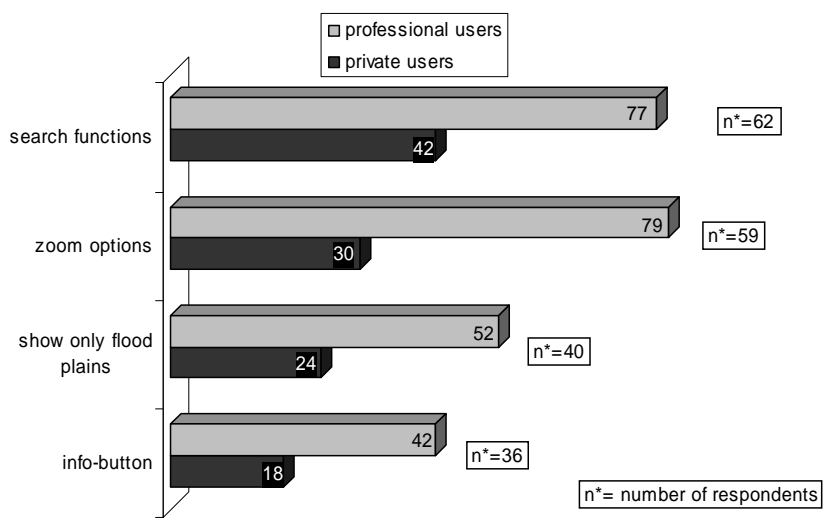

Fig. 12. Use of functions divided into professional and private users in percent.

the private users tended to give less positive evaluations than the professional users. Although not all formulated expectations are fulfilled in the present IÜG version, $60 \%$ of all interviewees were (fully) satisfied with the information included in the IÜG and only $17 \%$ indicated dissatisfaction. For example, current water levels and forecasts are only provided by the flood forecast centre (www.hnd.bayern.de).

Regarding whether the information was clearly arranged,the majority (65\%) gave positive assessments. Equally, the visual presentation was evaluated positively by $67 \%$ of the survey participants. These characteristics were judged in the same way by the two user groups. With regards to functionality, the respondents had already used most of the functions which the present version of the IÜG offers. There were significant differences between the professional and the private users use with regards to the use of search functions, zoom options, as well as the print and information buttons. As shown in Fig. 12, the professional users used all functions twice as often as the private users. These results lead to the conclusion that private users mainly use the system cursorily.

Concerning the further development of the IÜG, 73\% of both groups of respondents would appreciate the possibility of three dimensional illustrations. Additionally, 91\% argue for the inclusion of the associated water depths in the flood plains. The inclusion of extensions of flood events with different return period was also welcomed by $87 \%$. Moreover, $83 \%$ judge the combination with real-time information such as up-to-date water levels, web cams, etc., as helpful (Fig. 13). However, these numbers should not be over interpreted. For example, $73 \%$ stated that they really needed a 3-D illustration. Nevertheless, they provide a ranking for the Bavarian Watershed Authority with regards to the decision of which tool should be implemented first. Summing up, 99\% of the survey participants would recommend the web mapping service IÜG to a friend or a colleague when searching for flood information. This is a rather positive result. However, there are diverse aspects for enhancement.

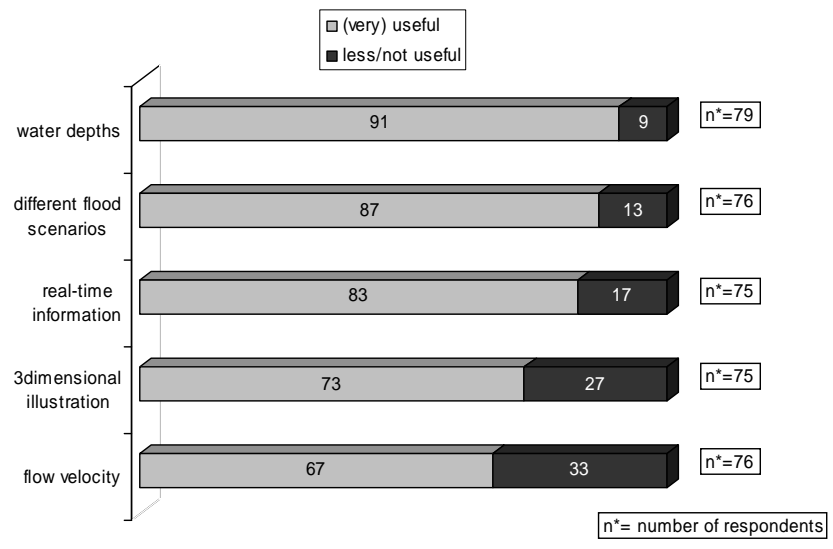

Fig. 13. Usefulness of possible enhancements in percent.

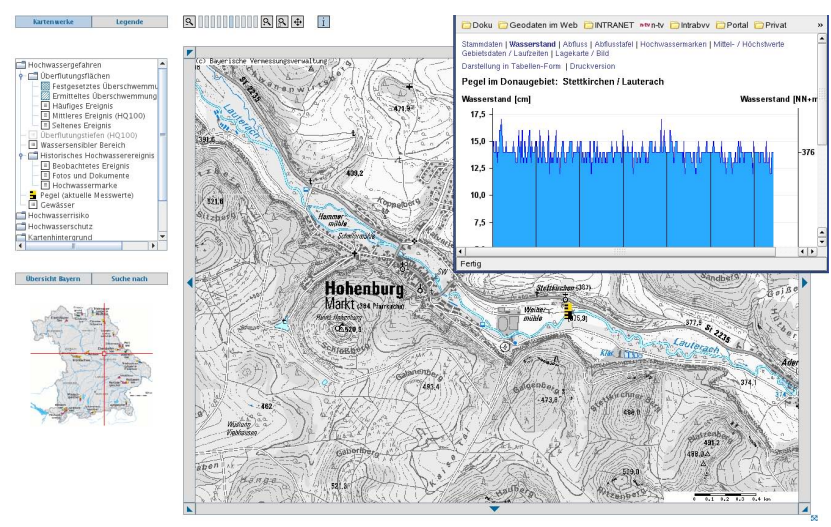

Fig. 14. Screenshot of current working status of the upcoming Bavarian Web Mapping Service IÜG (linkage to water levels, overview).

\subsection{Development of the Bavarian web mapping service on the basis of the formative evaluation}

According to the dynamic-transactional approach, the information communicated to the general public by flood related authorities has to be adapted to the needs and requirements of the users to be as effective as possible. The usability, readability, and the content of the Internet web mapping services are very important characteristics. This information given by the authorities, aims at increasing knowledge concerning floods and risk awareness. Therefore, the results of the formative evaluation on flood hazard maps and associated web mapping services were directly integrated into the development of the new Bavarian web mapping service. Figures 14-16 show screenshots of the current status. The users' requirements and expectations of a combination of flood hazard maps with real time information on gauge levels is made possible by directly linking gauge stations with the flood forecast centre. The links are illustrated with yellow-black gauge boards in the viewer (Fig. 14). To meet the request 


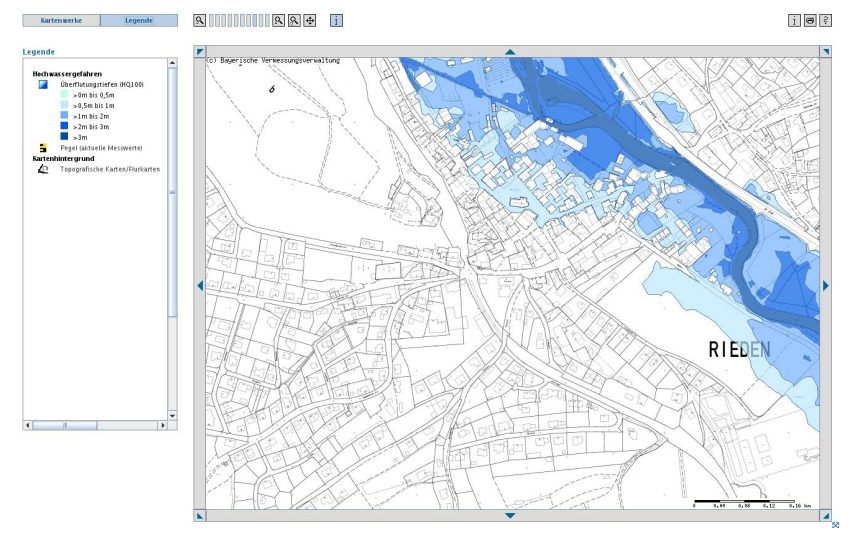

Fig. 15. Screenshot of current working status of the upcoming Bavarian Web Mapping Service IÜG (water depths on digital land register map).

for three-dimensional illustrations, the map currently shown in the viewer can be exported into a three-dimensional pdffile or into Google Earth as a kml-file. The plan is to show three different flood events and associated water depths as is requested by the EU Flood Directive and by the current users. Of course, the illustration will be done in blue colours to enhance the association with water (Fig. 15). The water flow velocity will not be integrated into the public viewer because this information is not usually needed by the private users. Where appropriate data is available, the extension of past flood events ideally connected with real pictures of these disasters will be included. Real flood events have a much stronger influence on building an awareness of flood risk perception than the flood events only derived from hydraulic modelling (see e.g. Wagner (2004) for the role of local disaster pictures to increase the attraction power of information tables about natural hazards). It will be possible to choose from different base maps such as the digital land register map, the digital city plan, or a black and white orthophoto (Fig. 16). Moreover, easily usable zoom and search functions will be offered.

\section{Conclusion and recommendations}

The results of the formative evaluation show that there are very different requirements and needs from various user groups to be fulfilled by flood maps and web mapping services. Therefore, a target group oriented risk communication is necessary to meet the group-specific demands. The general public, especially the people at risk, is one of the most important user groups because they are directly confronted with flood events, flood damages, consequences of legal obligations, or technical and non-structural protection measures (Excimap, 2007). The European flood policy has acknowledged this reality and the EU Flood directive precisely formulates the demand for risk communication with the general

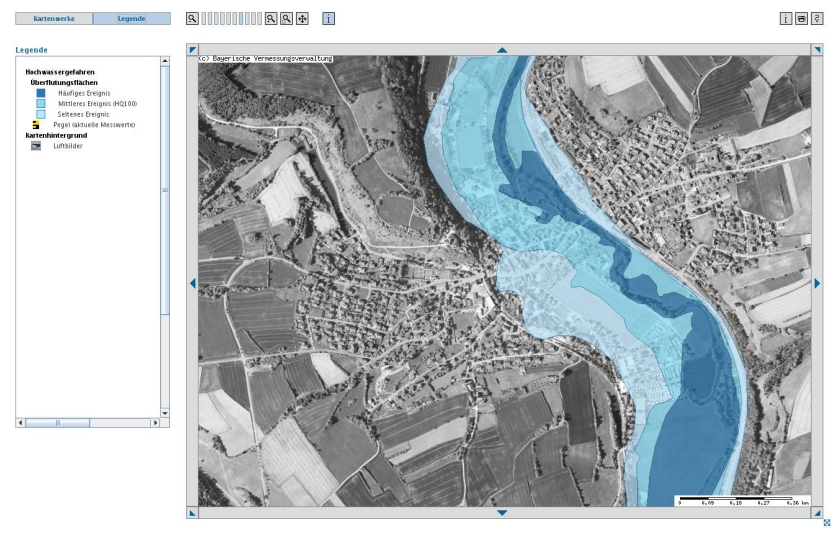

Fig. 16. Screenshot of current working status of the upcoming Bavarian Web Mapping Service IÜG (different scenarios on orthophoto).

public. Moreover, the general public should be increasingly involved in flood protection and should take responsibility for its own protection. The political strategy is to give up full responsibility for flood safety and encourage the people at risk to implement their own protection measures.

Risk communication has to focus not only on information activities but also on increasing risk awareness. Over time, the memory of the last flood event fades and the population at risk loses its risk awareness. Wagner (2004) has coined the term "half-time of oblivion". For successful and effective risk communication, and to update flood risk awareness, it is necessary to combine different kinds of communication and information tools to find new, regular, and repeated ways of activating recipients, and to address the different target groups. According to the dynamic-transactional approach, effective risk communication can lead to a high attention level and growing interest in flood topics triggering further information seeking, deeper engagement and growing acceptance (Früh and Schönbach, 2005). With this, well designed and target group specific flood risk communication can help to raise knowledge and preparedness. Flood maps as an information tool in risk communication is one way to fight against the typical human characteristics of neglecting and denying.

The dissemination of flood maps via the Internet is a very important way of bringing flood information to the public. Of course, hard copies are still needed, because not all people are connected to the Internet yet. This recommendation is also formulated by EXCIMAP (2007) which argues for actively promoting information about the availability of flood maps, web mapping services or Web GIS. Installations in towns or in the countryside, which show the extent, or the water depth, of the floodplain, such as flood tables or the "flood box", can be used to inform the public about the newly developed flood maps. The flood box is a telephone box, which was redesigned within the project FloodScan as 
a touring exhibition including an audio point with features about the local flood hazard and ways of preparing for actions.

Summing up, the following recommendations can be made. Information tools have to create emotional empathy and refer to the local situation. Moreover, risk communication has to be easily understandable to the people at risk. This means avoiding technical and statistical terms such as the "one hundred year flood". If you cannot avoid technical terminology, it has to be explained in a simple way and at sufficient length. In addition, an ongoing monitoring of risk communication measures and continuous feedback to the recipients are important success factors.

Relating to web mapping services or web based geographic information systems, it is crucial to link the illustrated maps of flood plains or flood risk zones with real time information such as water levels. Moreover, at the very least, water depths for flood events with different occurrence probabilities should be marked. Flood maps should be marked with a blue colouring so as to use the natural association of the colour blue with water. Additionally, the flood plains of flood events with high, medium and low probability should be marked, not only the flood plain of the one hundred year flood (HQ 100).

Our study mainly addresses the communication between authorities and the general public about floods, especially via flood maps. As a continuing study, it would be interesting to investigate the impacts on the addressees of the flood maps with regard to higher risk awareness and increased personal responsibility.

Edited by: R. Kirnbauer

Reviewed by: anonymous referees

\section{References}

ARD/ZDF: Online-Studie 2003: Internetverbreitung in Deutschland, 2003.

Atlas Kärnten: http://gis.ktn.gv.at/atlas/ (S(0vknwzeqrmwx1z552b2qxkvc))/init.aspx, access: 20 September 2008.

Barth, M.: Neue Medien in der Umweltkommunikation, INFUDiskussionsbeiträge 22/04, 2004.

BMU (German Federal Ministry for the Environment, Nature Conservation and Nuclear Safety): Entwurf Umweltgesetzbuch (UGB) Zweites Buch (II) - Wasserwirtschaft - Stand 20.5.2008, http://www.bmu.de/files/pdfs/allgemein/application/ pdf/ugb2_wasserwirtschaft.pdf, access: 20 September 2008.

CRUE ERA-NET: Crue snapshot: Highlighting flood-related research across Europe, 1 issue August 2008.

Environment Agency (UK): http://www.environment-agency. gov.uk/maps/info/floodmaps/?-version=1\&lang=_e, access: 20 September 2008.

EU: Commission staff working document accompanying the green paper from the Commission to the Council, the European Parliament, the European Economic and Social Committee and the
Committee of the Regions Adapting to climate change in Europe - options for EU action (COM(2007)354 final), 2007.

EXCIMAP (European Exchange Circle on Flood Mapping): Handbook on good practices for flood mapping in Europe, 2007.

Flood Map Environment Agency: http://maps.environment-agency. gov.uk/wiyby/mapController, access: 20 September 2008.

Früh, W. and Schönbach, K.: Der dynamisch-transaktionale Ansatz III: eine Zwischenbilanz, Publizistik, 50(1), 4-20, 2005.

Früh, W. and Schönbach, K.: Der dynamisch-transaktionale Ansatz, Ein neues Paradigma, der Medienwirkungen, Publizistik, 27, 74 $88,1982$.

Hagemeier-Klose, M.: Hochwasser - Risikowahrnehmung und Risikohandeln, Eine empirische Studie zur "Großen Flut 2002" in Ostdeutschland, VDM-Verlag Dr. Müller, Saarbrücken, Germany, 2007.

Hagemeier-Klose, M. and Wagner, K.: Experten-Evaluation von Web-GIS-Lösungen und Internetkartendiensten zur Kommunikation von Hochwasserinformationen, Geographica Helvetica, 63(2), 94-103, 2008.

Hertel, R. F. and Henseler, G. (Eds.): ERiK - Entwicklung eines mehrstufigen Verfahrens der Risikokommunikation, Schriftenreihe des Bundesinstituts für Risikobewertung, Germany, 2005.

Hochwassergefahrenkarten (Flood Hazard Maps) BadenWürttemberg: http://www.hochwasser.baden-wuerttemberg. de/servlet/is/15783, access: 20 September 2008.

Hochwassergefahrenkarten der Stadt Köln (Flood Hazard Maps of the City of Colgne): http://www.hw-karten.de/koeln/, access: 20 September 2008.

Hochwassernachrichtendienst Bayern (Flood Information Service of Bavaria): www.hnd.bayern.de, access: 20 September 2008.

Informationsdienst Überschwemmungsgefährdete Gebiete in Bayern (Information Service Flood Plains and Flood Prone Areas in Bavaria: www.bayern.de/LFW/iug/, access: 20 September 2008.

Jungermann, H. and Slovic, P.: Die Psychologie der Kognition und Evaluation von Risiko, in: Risiko und Gesellschaft, edited by: Bechmann, G., Opladen, Germany, 167-207, 1993.

Kienholz, H. and Krummenacher, B., Schweizer Bundesamt für Umwelt, Wald und Landschaft: Symbolbaukasten zur Kartierung der Phänomene, Bern, Switzerland, 1995.

LAWA Bund/Länder-Arbeitsgemeinschaft Wasser: Empfehlungen der Bund /Länder-Arbeitsgemeinschaft zur Aufstellung von Hochwasser-Gefahrenkarten, Brochure, Germany, 2007.

Lopes, R.: Public perception of disaster preparedness presentations using disaster damage images, Natural Hazards Research and Applications Information Center, Working Paper No. 79, Boulder, Colorado, USA, 1992.

PLANAT: Hochwassergefahren in der Schweiz - Risikobewusstsein in der Bevölkerung und die Implikationen für eine erfolgreiche Risikokommunikation, Final Report, 2004.

Project FloodScan: www.wzw.tum.de/floodscan/, access: 20 September 2008.

Ruhrmann, G.: Risikokommunikation, in: Öffentliche Kommunikation, edited by: Bentele, G., Brosius, H.-B., and Jarren, O., Wiesbaden, Germany, 539-549, 2003.

Schönbach, K. and Früh, W.: Der dynamisch-transaktionale Ansatz II: Konsequenzen, in: Das dynamisch- transaktionale Modell, Theorie und empirische Forschung, edited by: Früh, W., Opladen, Germany, 41-58, 1991.

Schrems, J.: Die Sicherheitskompetenz der Forstwirtschaft in 
Österreich, Ph.D thesis, Universität für Bodenkultur Wien, Austria, 1998.

Siegriest, M. and Gutscher, H.: Flooding Risks: A Comparison of Lay People's Perceptions and Expert's Assessments in Switzerland, Risk Analysis, 26(4), 971-979, 2006.

Slovic, P.: Perception of Risk, Science, 236, 280-285, 1987.

Steinführer, A., Kuhlicke, C., De Marchi, B., Scolobig, A., Tapsell, S., and Tunstall, S.: Towards flood risk management with the people at risk: from scientific analysis to practice recommendations (and back), in: Flood Risk Management: Research and Practice, edited by: Samuels, P., Huntington, S., Allsop, W., and Harrop, J., CD-Rom, Leiden: CRC Press/Balkema, 945-955, 2008.

Wagner, K.: Naturgefahrenbewusstsein und -kommunikation am Beispiel von Sturzfluten und Rutschungen in vier Gemeinden des bayerischen Alpenraums, Ph.D. thesis, TU München, Germany, 2004.

Wiedemann, P. M. and Schütz, H.: Developing Dialogue-Based Communication Programmes, Arbeiten zur Risikokommunikation des Forschungszentrums Jülich, No. 79, 2000.

Wiedemann, P. M. and Mertens, J.: Sozialpsychologische Risikoforschung Technikfolgenabschätzung, Theorie und Praxis, 14(3), 38-45, 2005.
Wottawa, H. and Thierau, H.: Lehrbuch Evaluation, 3rd edn., Bern, Göttingen, Toronto, Seattle, 2003.

Zwick, M. and Renn, O.: Risikokonzepte jenseits von Eintrittswahrscheinlichkeit und Schadenserwartung, in: Naturrisiken und Sozialkatastrophen, edited by: Felgentreff, C. and Glade, T., Spektrum, Berlin, Germany, 77-97, 2008.

\section{Legislation}

Europe: EU Flood Directive - Directive 2007/60/EC of the European Parliament and the Council of 23 October 2007 on the assessment and management of flood risks.

Germany: WHG - Wasserhaushaltsgesetz in der Fassung der Bekanntmachung vom 19 August 2002 (BGBl. I S. 3245), zuletzt geändert durch Artikel 2 des Gesetzes vom 10 Mai 2007 (BGBl. I S. 666)

Switzerland: RPG - Bundesgesetz über die Raumplanung vom 22 Juni 1979. Fassung gemäss Ziff. I des BG vom 6 Okt. 1995, in Kraft seit 1 Jan. 1997 (AS 1996965 966; BB1 1994 III 1075). 